\title{
Incidence of anti-HBC antibody (IgG and IgM) among HBsAg negative apparently healthy blood donors
}

\author{
Nittyananda Shil, Jolly Biswas, Ayesha Khatun, Atiar Rahman, Nahid Sultana, Fatema Easmin \\ and Sonia Sormin
}

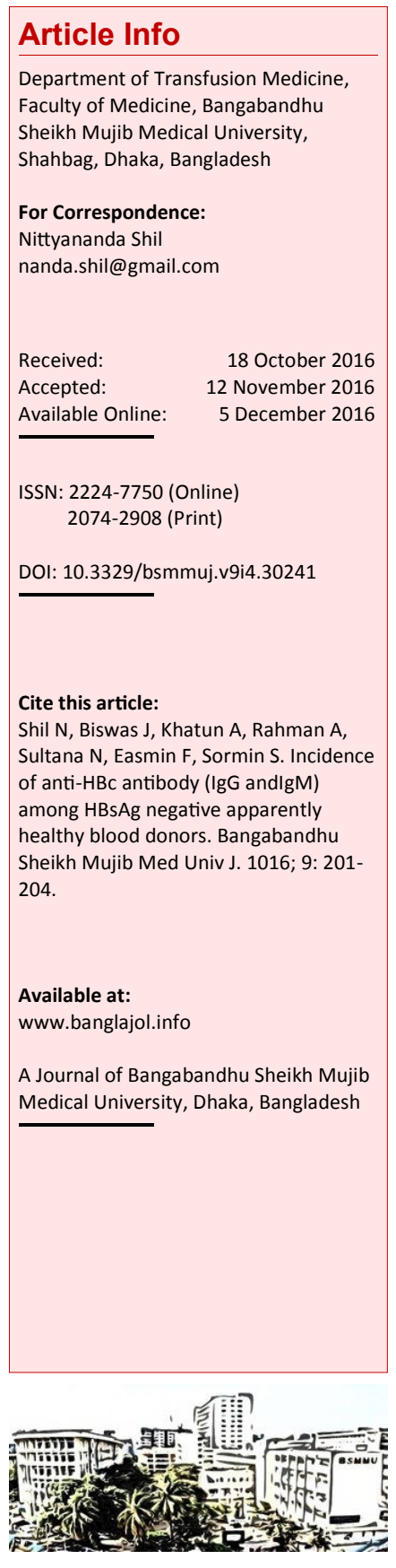

\section{Abstract}

In person who is unable to produce $\mathrm{HBsAg}$, anti-HBc antibody is a helpful marker of hepatitis B virus (HBV) infection. In the present study, we have tried to find out the incidence of anti-HBc (IgG and IgM) among blood donors HBsAg negative. People came for donating blood voluntarily or for their relatives $(n=1000)$ was selected on inclusion and exclusion criteria. Purposefully selected and collated samples were first tested by HBsAg ELISA of third generation reagent. HBsAg negative sample was tested with anti-HBc ELISA. Positive found in the first test was retested. Out of 1,000 samples on duplicate test, 117 positives were detected. The incidence of antiHBc antibody among apparently healthy blood donors was found $11.7 \%$.

\section{Introduction}

HBsAg is the first marker to appear in the blood, which persists, throughout the period of infectivity and eventually marks for chronic infection.1,2 In chronic carrier, HBsAg is eventually lost and replaced by anti-HBS. But within this, there is a period (diagnostic not detected by HBsAg window). .3 But anti-HBc antibody is detected in all persons who are infected with Hepatitis B virus (HBV). 4 In acute infection, high levels of IgM anti-HBc appear which persist for 3-4 months and are then replaced by IgG anti-HBc. High titer of IgG anti -HBc can be found in carriers. During the recovery phase of acute hepatitis $\mathrm{B}$, anti-HBc may be present in the absence of $\mathrm{HbsAg}$ and anti-HBS. .5 Donations during this time (window period) can transmit $\mathrm{HBV}$ (tail end carriers).6,7 Anti-HBc may be the only circulating marker in such individual and they may only be identifiable by anti-HBc screening or by anti$\mathrm{HBc}$ and HBsAg screening. In addition, anti$\mathrm{HBC}$ screening having value in the detection of $\mathrm{HBV}$ infected donor who have mutant HbsAg not detectable by some HbsAg assay. In a small proportion of carriers, only anti-HBc can be detected in the plasma. Such subjects may transmit HBV by transfusion. 8

In acute infection, high level of IgM anti-HBc have been found which persists for 3-4 months and then replaced by IgG anti-HBc. High titer of IgG anti-HBc can be found in carriers who may have low levels of IgM anti-HBc. So, mixed IgG and IgM assay is beneficial. It will detect both acute and chronic infection.

If anti-HBc can be detected in the plasma, such subjects may transmit HBV by transfusion. Subjects infected with HBV may be HBsAg negative due to point mutation in the precore region which may result in inability to synthesize HBsAg. Fulminant HBV infection developed in recipient of $\mathrm{HBsAg}$ negative blood from donors infected with this mutated virus. In all these donors, high levels of anti$\mathrm{HBc}$ are present. 9

About $50 \%$ of cases of HBV that could be transmitted by blood from HBsAg negative donors can be prevented by screening for antiHBc. $\underline{4}$

So, anti-HBc screening, in addition to HBsAg, may help in reducing $\mathrm{HBV}$ transmission by transfusion.

\section{Materials and Methods}

This cross-sectional study was conducted from July 2015 to June 2016. One thousand cases of HBsAg ELISA negative samples of blood donors (properly selected on inclusion and exclusion criteria and properly screened for human immunodeficiency virus (HIV), hepatitis $\mathrm{C}$ virus (HCV), HBsAg, syphilis and malaria by rapid immunochromatographic tests) were included. 


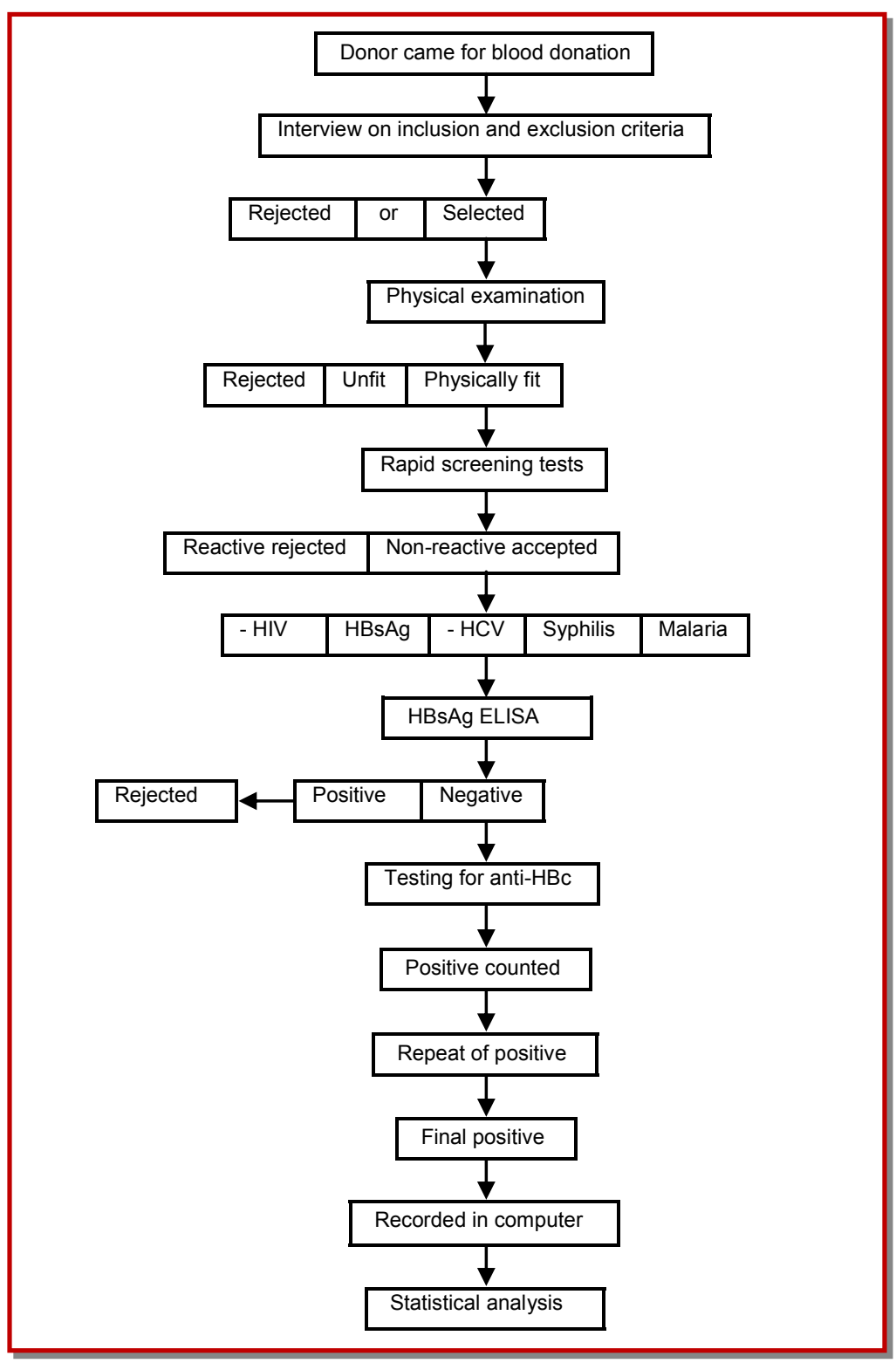

Figure 1: Study design

Inclusion criteria were a) Adult blood donor within the age limit of 18-60 years, b) Donors may have previous history of jaundice, but now physically fit for donation, c) Weight above $45 \mathrm{~kg}$, d) Hemoglobin value $>12 \mathrm{~g} / \mathrm{dL}$, e) Oral temperature of $97-99^{\circ} \mathrm{F}, \mathrm{f}$ ) Blood pressure systolic $100-200 \mathrm{~mm} \mathrm{Hg}$ and diastolic 60-100 $\mathrm{mmHg}$ without drug, g) Pulse 60100/ min, and h) HBsAg negative by ELISA.

Exclusion criteria were a) Under age 18 years and over 60 years, b) Weight less than $45 \mathrm{~kg}, \mathrm{c}$ ) cardiovascular diseases, d) History of surgery within one year with blood transfusion, e) History of blood transfusion for one year, f) Acupuncture, tattoo, ear or body piercing within 6 month and g) History of any known exposure to $\mathrm{HBV}$ and risk factor.
The selected donors by interview with the help of a written questioner was then examined for physical fitness for donation was determined (Figure 1). These selected donor samples were collected in a $4 "$ test tube with a identification serial number $5 \mathrm{~mL}$ of whole blood collected and left for 24 hours at $4^{\circ} \mathrm{C}$. Thereafter, the serum samples were separated and kept in Eppendrof tube and stored at below $-20^{\circ} \mathrm{C}$. When more than 90 samples were collected, they were tested for HBsAG-ELISA. For HBV, HIV, $\mathrm{HCV}$, malaria and syphilis, departmental usual rapid screening process was followed.

\section{ELISA testing for $\mathrm{HBs} A \mathrm{~g}$}

HBsAg was tested by ELISA method using commercial ELISA reagents of One step ELISAHBsAg of Delta Biologicals, Italy of 3rd generation (sensitivity $100 \%$ and specifity $99.5 \%$ ) Company's instruction was fully followed. HBsAg positive samples were disposed and new samples were included in the study with the same serial identification number. This is the final sample. Information about samples was noted in computer especially HBsAg and $\mathrm{H} / \mathrm{o}$ jaundice.

\section{ELISA testing for anti-HB $\mathrm{B}_{\mathrm{C}}$ antibody}

It was done with ELISA reagents of JAJ, USA. Samples positive were repeated. Repeated positives were taken as positive. Sensitivity of the reagent was not clearly cited in literature. Company's instructions were followed.

\section{Results}

Most of the donors $(n=963)$ belonged to age group of $18-30$ years (Table I). Similarly, $91.5 \%$ were males. About $50 \%$ were students.

Out of 1000 samples on duplicate test 117 samples were found positive for anti-HBc (IgG and IgM). The incidence was 11.7 percent. History of jaundice was found more among males $(3.6 \%)$ than females $(1.2 \%)$.

Anti-HBc antibody was found more among donors with the history of jaundice $(3.3 \%)$ than that of females $(0.3 \%)$. Donors having anti-HBc positive but no history of jaundice was among males $7.2 \%$ and among females 0.90 percent.

\section{Discussion}

Anti-HBc is found in all persons infected with $\mathrm{HBV}$. Anti-HBc detects mainly HBV infection at diagnostic window period. It is only the HBV marker at the recovery phase of acute $\mathrm{HBV}$ infection. Anti-HBc is produced in the plasma shortly after HBsAg and remain in the circulation for 3-4 months. It may be 
Table I

Parameters of patients

\begin{tabular}{|lr|}
\hline Parameters & $\mathrm{n}$ \\
\hline Age (years) & \\
$18-30$ & 963 \\
$31-60$ & 37 \\
Sex & \\
Male & 915 \\
Female & 85 \\
Occupation & \\
Student & 515 \\
Business & 198 \\
Private job & 133 \\
Government job & 87 \\
Physical labor & 54 \\
House wife & 13 \\
\hline
\end{tabular}

the only marker present in window period. It may be the only marker present in mutant HBV infection. HBsAg negative person but$\mathrm{HBc}$ positive does not require vaccination. Highly sensitive HBsAg ELISA cannot detect mutant HBsAg, Here- $\mathrm{HBc}$ is the only marker except DNA. HBV can be transmitted by many other ways like blood transfusion, surgery, dental procedure, long contact with a HBV infected person, etc. Family history is an important risk factor. These risk factors were excluded in this study by donor selection process. In acute infection, high level of IgM anti-HBc is present which is replaced by $\operatorname{IgG}$ anti-HBc. High titer of IgG anti-HBc can be found in carriers in the absence of HBsAg and anti-HBS. Donations taken at this period may cause PTH. In a small proportion of carriers only anti-HBc can be detected in plasma. Such subjects can transmit HBV by transfusion. So, in addition to $\mathrm{HBsAg}$, anti-HBc can detect $\mathrm{HBV}$ infection in blood transfusion donor. In present study, highly sensitive HBsAg ELISA reagent (sensitivity 100\%) was used. All noticeable risk factors were excluded from donors except history of jaundice, then anti-HBc was tested incidence found was $11.7 \%$. Incidence was higher among aged donors than the young donors and the male than female. High incidence was among the illiterate person. World wide prevalence/incidence having different figure. In Pakistan it is $17.3 \% . \underline{10}$ In Spain, it is $4.8 \%$ among $>65$ years of donors. In literature, it is found that the isolated prevalence of anti-HBc is supposed to be 4$50 \%$ depending on sensitivity of reagent, age of donor. But the incidence of false positive is $11-3 \%$ found in 20 years prospective study. In North-West Greece, the incidence is $15.8 \% . \underline{11}$ In Italy identified mutant $\mathrm{HB}$ anti-HBc prevalence is 4.8.11 They proposed not to use mutant $\mathrm{HB}$ donor blood for transfusion.

Now the question is whether can we propose to include anti-HBc as screening test in addition to HBsAg As, the reagent require repeated test, single test will loss huge number of valuable donors. There is no more record in our country about actual incidence/prevalence of anti-HBc. So, we cannot propose to include anti-HBc as screening of blood donor in addition to HBsAg. Now HB NAT is a alternative. But it require research about the new screening method. The cost of anti-HBc per test is not very high. But HBNAT is costly. But only HBsAg is not sufficient.

We will have to decide which will be included or added in addition to HBsAg, HBsAg may be added to NAT or anti-HBc. In India, They are trying to include NAT with HBsAg. But NAT plus anti-HBc greatly raise blood safety $\underline{12}$ but of high cost. There is another benefit, about $50 \%$ of cases of HBV transmitted from HBsAg negative donors can be prevented by using anti-HBc testing. It is usually due to mutant $\mathrm{HBV}$ transfusion from HBsAg negative donor.12 A study about mutant HBV patient is essential.

\section{Conclusion}

The prevalence of anti-HBc Ab was high (11.7\%) in Bangladeshi blood donors.

\section{Acknowledgement}

We will thank all investigators and staff of Transfusion Medicine BSMMU for their cooperation in the performance of the study.

\section{References}

1. Rinker J, Galambos JT. Prospective study of hepatitis B in thirty two inadvertently infected people. Gastroenterology 1981; 81: 686-91.

2. Zuckerman AJ. Viral hepatitis. Br Med Bull. 1990; 46: 1-564.

3. Dodd Ry, Notari EP, Stramer SL. Current prevalence and incidence of infections disease markers and estimated window period risk in the American red cross blood donor population. Transfusion 2002; 42: 975-79.

4. Mosley JW, Stevens CE, Aach RA, Hollinger FB, Mimms LT, Solomon LR, Barbosa LH, Nemo GJ. Donor screening for antibody to hepatitis $B$ core antigen and hepatitis B virus infection in transfusion recipients. Transfusion 1995; 35: 5-12.

5. Takahassi $K$, Imai $M$, Nomura $M$, Oinuma A, Machida A, Funatsu G, Miyakawa Y, Mayu$\mathrm{mi}$ M. Demonstration of the immunogenecity of hepatitis B core antigen in a hepatitis B e antigen polypeptide (P-19). J Gen Virol. 1981; 57: 325-30.

6. Hoofnagle JH. Post-transfusion hepatitis B. Transfusion 1990; 30: 384-86.

7. Hoofnagle JH, Saeff LB, Bales JB, Zimmerman $\mathrm{HJ}$, and the Veterans Administration Hepatitis Cooperative Study Group. Type B hepatitis after transfusion with blood containing antibody to hepatitis B core antigen. N Eng J Med. 1978; 298: 1379-83.

8. Weare JA, Robertson EF, Madsen G, Hu R, Decker RH. Improvement in the specificity of assays for detection of antibody to hepatitis B core antigen. J Clin Microbiol. 1991; 29: 600-04.

9. Kojima M, Shimbu M, Tsuchimochi T, Koyasu M, Tanaka S, lizuka H, Tanaka T, Okatnoto $\mathrm{H}$ Tsuda F, Miyakawa Y, Mayumi M. Posttransfusion falminant hepatitis $\mathrm{B}$ associated with precore infective HBV mutants. Vox Sang. 1991; 60: 34-39. 
10. Bhatti FA, Ullah L, Salamat N, Ayub M, Ghani E. Anti-hepatitis B core antigen testing, viral markers and occult HBV infection in Pakistani blood donors: Implicaiton for transfusion practice. Transfusion 2007; 47: 74-79.

11. Zervou EK, Dalekos GN, Boumba DS, Tsianos EV
Value of anti-HBc screening of blood donors for prevention of $\mathrm{HBV}$ : Results of a 3 years prospective study. Transfusion 2001; 41: 652-58.

12. Roth WK, Weber M, Petersen D, Drosten C, Buhr S, Sireis W. NAT for $\mathrm{HBV}$ and anti-HBc testing increase. Transfusion 2002; 42: 869-75. 